\title{
Analisis Kualitas Makanan dan Perceived Value terhadap Kepuasan Konsumen pada Industri Rumah Makan
}

\author{
Clara Chandra Komala ${ }^{1}$, Nor Norisanti ${ }^{2}$, Asep M. Ramdan ${ }^{3}$ \\ ${ }^{123}$ Fakultas Ilmu Administrasi dan Humaniora, Univesitas Muhammadiyah Sukabumi \\ Email : claracandra04@gmail.com
}

\begin{abstract}
The purpose of this study was to analysis the effect of food quality and perceived value on consumer satisfaction in the restaurant industry. The sample used in this research was 98 respondents and data collection methods using a questionnaire. The method used in this study is the use the type of probability sampling includes in the simple random sampling. The analysis technique using validity test, reliability test, multiple linear regression analysis, including test coefficient of determination, multiple correlation coefficient, and simultaneous test (F test).

The results of the test coefficient of determination seen from value (Adjusted $R^{2}$ ) of 0,473 can be interpreted that the effect of Food Quality and Perceived Value on consumer satisfaction is 4,73\%. The remaining 52,7\% is influenced by other factors not explained in this study. Based on the multiple correlation coefficient test seen from the $R$ value of 0.696 , it shows that there is a strong relationship between food quality and perceived value with customer satisfaction. Based on the $F$ test the probability value sig. $0,000<0,05$, which means that together Food Quality (X1) and Perceived Value (X2) significantly influence customer satisfaction (Y).
\end{abstract}

Keywords : Food Quality, Perceived Value, Consumer Satisfaction.

Abstrak

Tujuan penelitian ini adalah untuk menganalisis pengaruh kualitas makanan dan perceived value terhadap kepuasan konsumen pada rumah makan. Sampel penelitian yang dipakai sebanyak 98 responden dan teknik pengumpulan data menggunakan kuesioner. Metode dalam penelitian ini menggunakan jenis sampel probability sampling termasuk kedalam simple random sampling. Teknik analisi yang digunakan adalah uji validitas, uji reliabilitas, koefisien korelasi ganda, analisis regresi linear berganda, termasuk uji koefisien determinasi, koefisien korelasi ganda, dan pengujian hipotesis menggunakan uji secara stimultan (uji F).

Hasil penelitian uji koefisien determinasi dilihat dari nilai (Adjusted $\mathrm{R}^{2}$ ) sebesar 0,473 dapat diartikan bahwa pengaruh Kualitas Makanan dan Perceived Value terhadap Kepuasan Konsumen adalah sebesar 4,73\%. Sisanya 52,7\% dipengaruhi oleh faktor-faktor lain diluar penelitian ini. Berdasarkan uji koefisien korelasi ganda dilihat dari nilai R sebesar 0,696, menunjukan bahwa terjadi hubungan yang kuat antara kualitas makanan dan perceived value dengan kepuasan konsumen. Berdasarkan uji $\mathrm{F}$ nilai probabilitas sig. $0,000<0,05$, yang berarti bahwa secara bersama-sama Kualitas Makanan $\left(X_{1}\right)$ dan Perceived Value $\left(X_{2}\right)$ berpengaruh secara signifikan terhadap kepuasan konsumen (Y).

Kata Kunci : Kualitas Makanan, Perceived Value, Kepuasan Konsumen.

() 2019 Jurnal Riset Inspirasi Manajemen dan Kewirausahaan

\section{PENDAHULUAN}

Perkembangan sektor usaha industri makanan dan minuman di Indonesia saat ini mengalami peningkatan yang cukup pesat. Dalam beberapa tahun ini berdasarkan Badan Pusat Statistik (BPS), pertumbuhan indutri pengolahan nonmigas sebesar 5,14 persen pada kuartal IV tahun 2017, lebih tinggi dibanding periode tahun 2016 sebesar 3,91 persen. Pertumbuhan tertinggi pada kuartal IV/2017, yaitu industri makanan dan minuman sebesar 13,14 persen, industri mesin dan perlengkapan 9,51 persen, indutsri logam dasar 7,05 persen, serta industri tekstil dan pakaian menjadi 6,39 persen. Bisnis rumah makan dan restoran adalah industri global dengan persaingan yang sengit dan ketat (Harrington, Ottenbacher \& Kendall , 2011), karena merupakan salah satu usaha yang sangat menjanjikan.

Persaingan bisnis rumah makan dan restoran yang semakin ketat menjadi suatu tantangan ataupun ancaman bagi para pelaku bisnis. Agar dapat bertahan dalam ketatnya persaingan, para pelaku bisnis diharuskan mempunyai insting yang sangat kuat dan peka terhadap perubahanperubahan yang terjadi pada pasar yang sudah ada, serta dituntut untuk mempunyai strategi yang baik guna dapat memenuhi dan menanggapi setiap tuntutan konsumen yang terus berubah. Banyak 
perusahaan harus menempatkan orientasi kepada kepuasan konsumen sebagai tujuan utama (Soekresno, 2000:15).

Kepuasan konsumen saat ini menjadi sebuah asset yang sangat penting bagi kesenjangan perusahaan terutama pada industri rumah makan. Banyaknya topik penelitian mengenai kepuasan konsumen peneliti mengkaji, selama 10 tahun terakhir. Berdasarkan datanya dari data (Wury Indahsari Putri, 2014), (Ndaru Prasastonodan Sri dan Yulianto Fajar Pradapa 2012), (Sova Adi Christianto 2012), (Jeewon Choi et al., 2008), (Eduard Cristobal et al., 2007), (Yang dan Fang 2004), (Margaretha dan Edwin 2012), (Alida Palitali 2007).

Kepuasan konsumen adalah perasaan senang atau kecewa seseorang yang muncul setelah membandingkan kinerja (hasil) produk yang dipikirkan terhadap kinerja yang diharapkan (Kotler dan Keller, 2016:153). Ketika konsumen melakukan pembelian, maka konsumen akan melakukan evaluasi seberapa tinggi harapannya bisa terpenuhi dari produk yang telah diterimanya. Ketika harapan-harapan konsumen terpenuhi, maka akan tercipta kepuasan konsumen dan jika tidak terpenuhi makan konsumen akan mengalami kekecewaan (Briandy dan Ritzky, 2015:2). Menurut Choi dan Kim (2013) bahwa tingkat kepuasan konsumen dari sebuah layanan tergantung dari value yang dirasakan oleh konsumen. Semakin tinggi value yang diterima konsumen maka kepuasan konsumen akan semakin meningkat (Norouzi, et al., 2013).

Menurut Kotler dan Keller (2016:151), menyatakan bahwa consumer perceived value adalah perbedaan antara evaluasi perspektif konsumen terhadap semua keuntungan (benefit) dan keseluruhan biaya dan dibandingkan dengan alternatif yang ada. Hasil penelitian Aan Nugroho (2013) menyatakan bahwa perceived value mempunyai pengaruh yang signifikan dalam menciptakan kepuasan pelanggan pada restoran.

Selain perceived value, rumah makan diharuskan mengutamakan kualitas makanan yang terbaik, karena kualitas makanan sebagai salah satu tolak ukur dalam upaya meningkatkan kepuasan konsumen (Dian Kristiana, 2013:3). Hasil penelitian Christianto (2013) menyatakan bahwa kualitas makan mempunyai hubungan secara signifikan terhadap kepuasan konsumen.

Kepuasaan dalam industri makanan tentunya berkaitan dengan kebutuhan yang ingin dipenuhi. Perusahaan berupaya memberikan kinerja yang baik sesuai harapan konsumennya, bahkan melebihi ekspetasi konsumen terhadap makanan dan minuman yang ditawarkan kepada konsumennya untuk menciptakan sebuah kepuasan, karena konsumen yang merasa puas akan berbagi rasa dan pengalamannyadengan merekomendasikan kepada teman terdekatnya. Akan tetapi, dalam upaya yang diberikan oleh perusahaan dalam meningkatkan kepuasan konsumen, faktanya yang terjadi tidak semua konsumen yang mengunjungi rumah makan merasa puas dengan apa yang sudah diberikan.

Tema yang diusulkan peneliti adalah Analisis Kualitas Makanan Dan Perceived Value Terhadap Kepuasan Konsumen Pada Industri Rumah Makan. Tujuan penelitian ini yaitu untuk mengetahui bagaimana pengaruh kualitas makanan dan perceived value terhadap kepuasan konsumen pada industri rumah makan.

\section{KAJIAN LITERATUR}

\section{Kualitas Makanan}

Kualitas makanan merupakan hal penting yang harus diperhatikan oleh rumah makan dan restoran dikarenakan makanan merupakan produk utama yang ditawarkan oleh rumah makan kepada konsumen mereka, sehingga rumah makan harus menjaga harapan konsumen mengenai kualitas dari produk yang ditawarkan oleh rumah makan kepada konsumen (Walter et al., 2010; Jang and Mankung, 2009).

Selain itu kualitas makanan merupakan karakteristik kualitas dari makanan yang dapat diterima oleh konsumen, seperti ukuran, bentuk, warna, konsistensi, tekstur, dan rasa (Andreas dan Stefanus, 2014:644). Menurut Essinger dan Wylie 2003, mereka membagi produk khususnya masakan atau makanan dalam beberapa kategori yaitu:

1. Rasa

Kualitas rasa yang dijaga dengan baik sesuai cita rasa yang diinginkan oleh konsumen (Kevin Hariyanto 2014:3), (Dewi Purnamawati, 2017:22).

2. Kuantitas porsi

Dalam setiap penyajian makanan sudah ditentukan porsi standarnya yang disebut standard portion size. Standard portion size didefinisikan sebagai kuantitas item yang harus disajikan setiap kali item tersebut dipesan (Kevin Hariyanto 2014:3), (Dewi Purnamawati, 2017:22).

3. Variasi menu

Variasi menu yang disajikan bermacammacam (Kevin Hariyanto 2014:3), (Dewi Purnamawati, 2017:22).

4. Citra rasa yang khas

Citra rasa yang khas dan unik yang berbeda dan hanya ada ditempat tersebut (Kevin Hariyanto 2014:3), (Dewi Purnamawati, 2017:22). 
5. Higienitas atau kebersihan

Kebersihan dalam penyajian makanan dan kualitas yang selalu dijaga (Kevin Hariyanto 2014:3), (Dewi Purnamawati, 2017:22).

6. Inovasi

Inovasi dari produk-produk baru yang ditawarkan membuat konsumen tidak bosan dengan produk yang monoton sehingga konsumen memiliki banyak pilihan (Kevin Hariyanto 2014:3), (Dewi Purnamawati, 2017:22)

\section{Perceived Value}

Perceived value merupakan perbedaan antara evaluasi perspektif konsumen terhadap semua keuntungan (benefit) dan keseluruhan biaya dan dibandingkan dengan alternatif yang ada (Kotler dan Keller 2016:151). Selain itu juga perceived value merupakan evaluasi menyeluruh dari kegunaan suatu produk yang didasari oleh persepsi konsumen terhadap sejumlah manfaat yang akan diterima dibandingkan dengan pengorbanan yang dilakukan (Kotler 2003:60), (Krisno dan Samuel, 2013), (Lai 2004).

Menurut Bimo Taufan Perwira (2016) menyatakan bahwa untuk mengetahui perceived value perusahaan harus memperhatikan empat aspek yaitu

1. Emotional Value : suatu keadaan dimana emosi yang timbul karena adanya nilai yang positif saat menggunakan produk ataupun jasa (Sweeney and Soutar 2001:208), (Tjiptono 2006).

2. Social Value : suatu keadaan dimana konsumen merasa tingkatan sosial meningkat saat menggunakan produk ataupun jasa (Sweeney and Soutar 2001:208), (Tjiptono 2006).

3. Performance : suatu keadaan dimana konsumen merasa ekspetasi yang diharapkan sesuai dengan apa yng didapatkan (Sweeney and Soutar 2001:208), (Tjiptono 2006).

4. Price/Value of Money : suatu keadaan dimana konsumen menilai tingkat efisiensi biaya dapat terpenuhi (Sweeney and Soutar 2001:208), (Tjiptono 2006).

\section{Kepuasan Konsumen}

Kotler dan Keller (2016:153), menyatakan Kepuasan konsumen adalah perasaan senang atau kecewa seseorang yang muncul setelah membandingkan kinerja (hasil) produk yang dipikirkan terhadap kinerja yang diharapkan. Menurut Mowen dan Minor (2002: 89) "Kepuasan pelanggan merupakan penilaian evaluatif pasca pemilihan yang disebabkan oleh seleksi pembelian khusus dan pengalaman menggunakan atau mengkonsumsi barang atau jasa tersebut".
Menurut Stella Lucia Indrata et al., 2017 menyatakan bahwa atribut pembentukan kepuasan terdiri dari :

1. Kesesuaian harapan

Yaitu tingkat kesesuaian diantara kinerja produk yang diharapkan dan dengan apa yang dirasakan oleh konsumen (Tjiptono 2004:101), dengan meliputi :

a. Yaitu berupa suatu produk yang diperoleh dengan sesuai atau melebihi yang diharapkan.

b. Yaitu pelayanan oleh pegawai yang diperoleh sesuai atau melebihi dengan yang diharapkan.

c. Fasilitas penunjang yang didapat sesuai atau melebihi dengan yang diharapkan.

2. Minat berkunjung kembali

Yaitu kesedian konsumen untuk berkunjung kembali atau melakukan pembelian ulang terhadap produk terkait (Tjiptono 2004:101), meliputi :

a. Berminat untuk berkunjung kembali karena pelayanan yang diberikan oleh pegawai memuaskan.

b. Berminat untuk berkunjung kembali karena nilai dan manfaat yang diperoleh setelah mengkonsumsi produk.

c. Berminat untuk berkunjung kembali karena fasilitas penunjang yang disediakan memadai.

3. Kesediaan merekomendasikan

Yaitu kesediaan konsumen untuk merekomendasikan produk yang telah dirasakannya kepada teman atau keluarga (Tjiptono 2004:101), meliputi:

a. Menyarankan teman atau kerabat untuk membeli produk yang ditawarkan karena pelayanan yang memuaskan.

b. Menyarankan teman atau kerabat untuk membeli produk yang ditawarkan karena fasilitas penunjang yang disediakan memadai.

c. Menyarankan teman atau kerabat untuk membeli produk yang ditawarkan karena nilai atau manfaat yang didapat setelah mengkonsumsi sebuah produk jasa.

Serta hubungan Kualitas Makanan (X1) dan Perceived Value (X2) terhadap Kepuasan Konsumen (Y). Menurut Qin et al., (2009:87) mendapatkan hasil yang positif bahwa kualitas pelayanan (service quality), kualitas makanan (food quality), dan nilai (perceived value) yang dirasakan merupakan anteseden yang cukup siginifikan terkadap kepuasan konsumen dalam industri makanan cepat saji. Kualitas makanan dan perceived value mempunyai peranan yang sangat mempengaruhi kepuasan konsumen. 
$\mathrm{H}_{1}$ : Kualitas Makanan dan Perceived Value Berpengaruh terhadap Kepuasan Konsumen pada industri rumah makan.

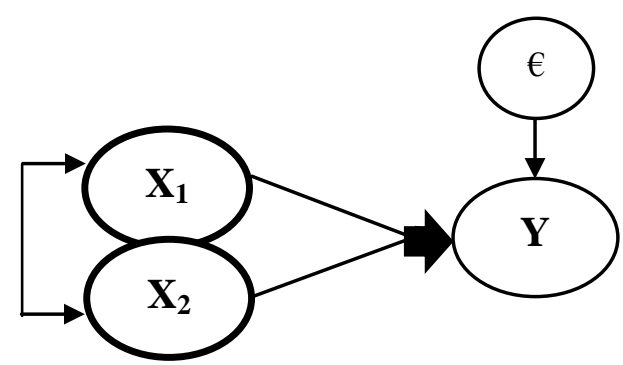

Gambar Paradigma Penelitian

Keterangan :

Variabel $\mathrm{X}_{1}=$ Kualitas Makanan

Variabel $\mathrm{X}_{2}=$ Perceived Value

Variabel Y = Kepuasan Konsumen

$€ \quad=$ Variabel lain diluar peneliti

\section{METODE PENELITIAN}

Penelitian ini dilaksanakan di PT. Triboga Jaya (RM. Sunda Rasa) Kota Sukabumi. Menggunakan pendekatan manajemen pemasaran, yang khususnya membahas tentang Kualitas Makanan, Perceived Value dan Kepuasan Konsumen. Dalam penelitian ini terdapat tiga variabel yang dijadikan kawasan penelitian yaitu Kualitas Makanan (Variabel X1), Perceived Value (Variabel X2), dan juga Kepuasan Konsumen (Variabel Y). dalam penelitian ini yang dijadikan variabel terikat (dependent variable) yaitu Kepuasan Konsumen, dan yang dijadikan variabel bebas (independent variable) yaitu Kualitas Makanan dan Perceived Value.

Penelitian yang dijadikan variabel bebas (independent variable) adalah kualitas makanan dan perceived value. Kualitas makanan terdiri dari enam dimensi, yaitu : rasa, kuantitas porsi, variasi menu, citra rasa khas, higienies dan inovasi. Sedangkan perceived value terdiri dari empat dimensi, yaitu : nilai emosional, nilai sosial, nilai terhadap harga dan nilai kualitas. Dan yang menjadi variabel terikat (dependent variable) adalah kepuasan konsumen yang meliputi tida dimensi, yaitu : kesesuian harapan, minat berkunjung kembali dan kesediaan merekomendasikan.

Populasi dalam penelitian ini adalah konsumen yang pernah berkunjung ke di PT. Triboga Jaya (RM. Sunda Rasa) Kota Sukabumi. Metode yang digunakan adalah menggunakan teknik probability sampling dengan metode pendekatan simple random sampling dan dengan melakukan penyebaran kuesioner sebanyak 98 kepada responden. Teknik analisis yang digunakan adalah uji validitas, uji reliabilitas, teknik analisis koefisien korelasi ganda, koefisien determinasi, regresi linear berganda dan pengujian hipotesis menggunakan uji secara simultan (uji F).

\section{HASIL PENELITIAN DAN PEMBAHASAN}

\section{Uji Validitas}

Uji validitas adalah suatu taraf di mana alat pengukur dapat mengukur apa yang seharusnya diukur sehingga suatu penelitian yang menggunakan kuesioner sebagian besar pengukurnya perlu diuji validitasnya. Biasanya syarat minimum untuk dianggap memenuhi syarat adalah kalau $r=0,3$. Jadi jika korelasi antara butir dengan skor total kurang dari 0,3 maka butir dengan instrumen dinyatkan tidak valid.

Berdasarkan pengujian validitas menggunakan bantuan software SPSS 24 diperoleh hasil sebagai berikut:

Tabel

Hasil Uji Validitas

\begin{tabular}{|c|c|c|c|c|}
\hline Variabel & Item & r-hitung & r-kritis & Ket \\
\hline \multirow{7}{*}{$\begin{array}{l}\text { Kualitas } \\
\text { Makanan } \\
\left(\mathrm{X}_{1}\right)\end{array}$} & 1 & 0,632 & 0,3 & Valid \\
\hline & 2 & 0,646 & 0,3 & Valid \\
\hline & 3 & 0,692 & 0,3 & Valid \\
\hline & 4 & 0,601 & 0,3 & Valid \\
\hline & 5 & 0,696 & 0,3 & Valid \\
\hline & 6 & 0,543 & 0,3 & Valid \\
\hline & 7 & 0,622 & 0,3 & Valid \\
\hline \multirow{9}{*}{$\begin{array}{l}\text { Perceived } \\
\text { Value }\left(\mathrm{X}_{2}\right)\end{array}$} & 1 & 0,567 & 0,3 & Valid \\
\hline & 2 & 0,664 & 0,3 & Valid \\
\hline & 3 & 0,632 & 0,3 & Valid \\
\hline & 4 & 0,648 & 0,3 & Valid \\
\hline & 5 & 0,601 & 0,3 & Valid \\
\hline & 6 & 0,626 & 0,3 & Valid \\
\hline & 7 & 0,636 & 0,3 & Valid \\
\hline & 8 & 0,687 & 0,3 & Valid \\
\hline & 9 & 0,573 & 0,3 & Valid \\
\hline \multirow{8}{*}{$\begin{array}{l}\text { Kepuasan } \\
\text { Konsumen } \\
\text { (Y) }\end{array}$} & 1 & 0,633 & 0,3 & Valid \\
\hline & 2 & 0,677 & 0,3 & Valid \\
\hline & 3 & 0,701 & 0,3 & Valid \\
\hline & 4 & 0,693 & 0,3 & Valid \\
\hline & 5 & 0,656 & 0,3 & Valid \\
\hline & 6 & 0,710 & 0,3 & Valid \\
\hline & 7 & 0,706 & 0,3 & Valid \\
\hline & 8 & 0,670 & 0,3 & Valid \\
\hline
\end{tabular}

Sumber : Data primer tahun 2019

\section{Uji Reliabilitas}

Hasil uji reliabilitas dengan menggunakan rumus Cronbach's Alpha serta dengan bantuan 
software SPSS 24 diperoleh hasil perhitungan yang disajikan pada tabel berikut ini :

\begin{tabular}{cccc}
\hline \multirow{2}{*}{ Variabel } & \multicolumn{2}{c}{$\begin{array}{c}\text { Koefisien } \\
\text { Cronbach's Alpha }\end{array}$} & \multirow{2}{*}{ Ket } \\
\cline { 2 - 3 } & Hitung & Standar & \\
\hline $\begin{array}{c}\text { Kualitas } \\
\text { Makanan }\left(\mathrm{X}_{1}\right)\end{array}$ & 0,751 & 0,6 & Reliabel \\
\hline $\begin{array}{c}\text { Perceived Value } \\
\left(\mathrm{X}_{2}\right)\end{array}$ & 0,803 & 0,6 & Reliabel \\
\hline $\begin{array}{c}\text { Kepuasan } \\
\text { Konsumen (Y) }\end{array}$ & 0,834 & 0,6 & Reliabel \\
\hline Sunn & & & \\
\hline
\end{tabular}

Sumber : Data primer tahun 2019

Dari tabel pengujian di atas diperoleh hasil yang menunjukkan $\alpha$ hitung $>\alpha$ standar $(0,6)$ sehingga dapat disimpulkan bahwa variabelvariabel yang dipakai dalam penelitian ini adalah reliabel. Dengan demikian maka jelaslah bahwa variabel-variabel tersebut dapat digunakan untuk penelitian selanjutnya karena dapat diandalkan.

\section{Koefisien Korelasi Ganda (R)}

Tabel

Hasil Koefisien Korelasi Ganda Model Summary

\begin{tabular}{|l|c|r|r|r|}
\hline Model & $\mathrm{R}$ & $\begin{array}{c}\mathrm{R} \\
\text { Square }\end{array}$ & $\begin{array}{c}\text { Adjusted } \\
\text { R Square }\end{array}$ & $\begin{array}{c}\text { Std. Error } \\
\text { of the } \\
\text { Estimate }\end{array}$ \\
\hline 1 & $.696^{\mathrm{a}}$ & .484 & .473 & 2.143 \\
\hline
\end{tabular}

a. Predictors: (Constant), Perceived Value, Kualitas Makanan

Sumber : Data primer tahun 2019

Berdasarkan tabel 5 diatas diperoleh angka $\mathrm{R}$ sebesar 0,696 berada pada kategori 0,60-0,799. Hal ini menunjukan bahwa terjadinya hubungan yang kuat antara kualitas makanan dan perceived value dengan kepuasan konsumen.

Koefisien Determinasi $\left(\mathbf{R}^{2}\right)$

\section{Tabel}

Hasil Koefisien Determinasi

Model Summary

\begin{tabular}{|l|c|r|r|r|}
\hline Model & $\mathrm{R}$ & $\begin{array}{c}\mathrm{R} \\
\text { Square }\end{array}$ & $\begin{array}{c}\text { Adjusted } \\
\text { R Square }\end{array}$ & $\begin{array}{c}\text { Std. Error } \\
\text { of the } \\
\text { Estimate }\end{array}$ \\
\hline 1 & $.696^{\mathrm{a}}$ & .484 & .473 & 2.143 \\
\hline
\end{tabular}

a. Predictors: (Constant), Perceived Value, Kualitas Makanan

Sumber : Data primer tahun 2019

Hasil tabel 4 diatas model summary menyatakan besarnya adjusted $\mathrm{R}^{2}$ sebesar 0,473 ; hal ini berarti $47,3 \%$ variasi kepuasan konsumen dapat dijelaskan oleh variasi dari dua variabel independen yaitu kualitas makanan dan perceived value sedangkan sisanya $52,7 \% \quad(100 \%$ $47,3 \%=52,7 \%$ ) dari faktor yang tidak diteliti.

\section{Hasil Analisis Regresi Linear Berganda}

Regresi linear berganda digunakan untuk mengetahui seberapa besar pengaruh faktor yang digunakan dalam model penelitian Kualitas Makanan dan Perceived Value terhadap Kepuasan Konsumen. Hasil regresi linear berganda dapat dilihat pada tabel sebagai berikut :

Tabel

Hasil Uji Regresi Linier Berganda

\begin{tabular}{|c|c|c|c|c|c|}
\hline \multicolumn{6}{|c|}{ Coefficients $^{a}$} \\
\hline \multirow[t]{2}{*}{ Model } & \multicolumn{2}{|c|}{$\begin{array}{l}\text { Unstandardized } \\
\text { Coefficients }\end{array}$} & \multirow{2}{*}{$\begin{array}{c}\begin{array}{c}\text { Standar } \\
\text { dized } \\
\text { Coefficie } \\
\text { nts }\end{array} \\
\text { Beta }\end{array}$} & \multirow[t]{2}{*}{$\mathrm{t}$} & \multirow[t]{2}{*}{ Sig. } \\
\hline & $B$ & $\begin{array}{l}\text { Std. } \\
\text { Error }\end{array}$ & & & \\
\hline $\begin{array}{l}1 \\
\text { (Constant) }\end{array}$ & 8.822 & 2.782 & & 3.171 & .002 \\
\hline $\begin{array}{l}\text { Kualitas } \\
\text { Makanan }\end{array}$ & .393 & .108 & .337 & 3.653 & .000 \\
\hline $\begin{array}{l}\text { Perceived } \\
\text { Value }\end{array}$ & .384 & .081 & .439 & 4.770 & .000 \\
\hline
\end{tabular}

Dari output uji regresi linear berganda diatas, maka dapat diperoleh persamaan sebagai berikut ini: $\mathrm{Y}=8.822+0,393 \mathrm{X}_{1}+0,384 \mathrm{X}_{2}$

\section{Uji Sigfikansi Secara Simultan (Uji F)}

Tabel

Hasil Uji F

ANOVA $^{\mathrm{a}}$

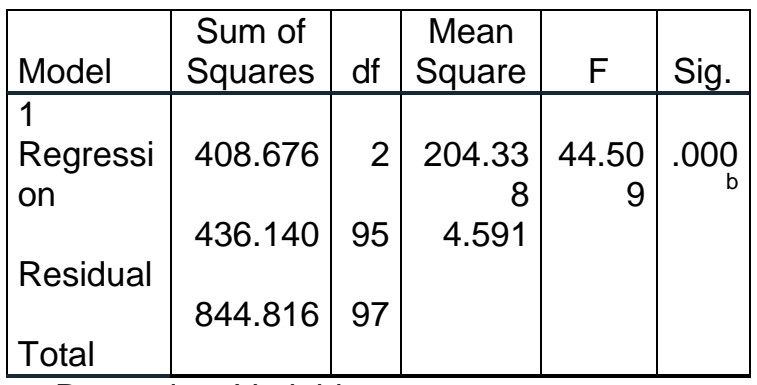

a. Dependent Variable:

Kepuasan Konsumen

b. Predictors: (Constant), Perceived Value,

Kualitas Makanan

Sumber : Data primer tahun 2019 
Hasil tabel 6 di atas, hasil uji $F$ hitung variabel $\mathrm{X}_{1}$ (Kualitas Makanan), $\mathrm{X}_{2}$ (Perceived Value) dan Y (Kepuasan Konsumen) adalah sebesar 44.509. maka dapat diperoleh nilai sig. $0,000<0,05$; nilai $\mathrm{F}_{\text {hitung }} 44.509>\mathrm{F}_{\text {tabel }}$ 2.36. Artinya bahwa kualitas makanan dan perceived value berpengaruh signifikan terhadap kepuasan konsumen.

Berdasarkan pada hasil hitungan penelitian analisis regresi berganda uji $\mathrm{F}$ dengan tingkat signifikan sebesar 0,1 (10\%) menunjukan bahwa variabel Kualitas Makanan $\left(\mathrm{X}_{1}\right)$ dan Perceived Value $\left(\mathrm{X}_{2}\right)$ berpengaruh secara bersama-sama terhadap Kepuasan Konsumen (Y). Hal ini ditunjukan dengan hasil nilai sig. $0,000<0,05$; nilai $F_{\text {hitung }} 44.509>F_{\text {tabel }}$ 2.36. Nilai Koefisien Determinasi $\left(\mathrm{R}^{2}\right)$ diperoleh hasil dari variabel Kualitas Makanan $\left(\mathrm{X}_{1}\right)$ dan Perceived Value $\left(\mathrm{X}_{2}\right)$ mempengaruhi sebesar 47,3\% $(0,473)$ terhadap Kepuasan Konsumen (Y), sisanya 52,7\% dipengaruhi oleh faktor-faktor lain diluar penelitian ini. Hal ini dikarenakan suatu Kualitas Makanan dan Perceived Value berperan penting dalam memberikan suatu kepuasan kepada konsumen. Dengan demikian dapat diketahui bahwa Kualitas Makanan $\left(\mathrm{X}_{1}\right)$ dan Perceived Value $\left(\mathrm{X}_{2}\right)$ merupakan faktor yang membentuk Kepuasan Konsumen (Y) Pada Industri Rumah Makan PT. Triboga Jaya (RM. Sunda Rasa) Kota Sukabumi secara simultan.

\section{PENUTUP}

\section{Kesimpulan}

1. Tiap-tiap indikator dari masing-masing variabel Kualitas Makanan $\left(\mathrm{X}_{1}\right)$, Perceived Value $\left(\mathrm{X}_{2}\right)$ dan Kepuasan Konsumen (Y) dalam penelitian ini dapat mewakili dari masing-masing variabelnya dan sekaligus dapat dihandalkan untuk dipergunakan sebagai indikator yang dapat digunakan oleh peneliti yang akan datang.

2. Berdasarkan uji F, variabel kualitas makanan dan perceived value berpengaruh signifikan terhadap kepuasan konsumen pada industri rumah makan PT. Triboga Jaya (RM. Sunda Rasa) Kota Sukabumi.

\section{Saran}

1. PT. Triboga Jaya Kota Sukabumi harus lebih meningkatkan lagi keinginan konsumen yang sesuai dengan harapan konsumen, seperti meingkatkan kualitas makanan sehingga konsumen akan merasa puas dengan pelayanan yang diberikan.

2. PT. Triboga Jaya Kota Sukabumi harus lebih memberikan perceived value atau nilai yang lebih dari yang diharapkan konsumen sehingga konsumen merasa puas dengan nilai yang diterima saat membeli produk yang ditawarkan.
3. PT. Triboga Jaya Kota Sukabumi harus lebih mendekatan diri dengan konsumen dengan begitu perusahaan dapat memahami masalahmasalah yang konsumen rasakan. Sehingga perusahaan dapat memahami keinginan dan kebutuhan konsumen, dan apakah konsumen merasa puas atau tidak terhadap kualitas makanan, perceived value yang telah diberikan kepada konsumen.

\section{DAFTAR PUSTAKA}

Adinugraha, Andreas Tanuel dan Stefanus Michael. (2014). Analisa Pengaruh Kualitas Makanan Dan Persepsi Harga Terhadap Kepuasan Konsumen D'cost Surabaya. Jurnal Manajemen Pemasaran.

Christianto, Sova Adi. (2012). Pengaruh Service Quality, Food Quality dan Perceived Value Pada Behavioural Intention yang Dimediasi oleh Customer Satisfaction (Studi pada Restoran Ayam-Ayam Resto Klodoran). Tesis. Fakultas Ekonomi Universitas Sebelas Maret Surakarta.

Choi, Jeewon; Seol, Hyeonjoo; Lee, Sungjo; Cho, Hyunmyung dan Park, Yongtae. (2008). Customer Satisfaction Factors of Mobile Commerce in Korea. Internet Research, Vol. 8 No.3 pg. 313335.

Cristobal, Eduard., Flavian, Carlos., and Guinaliu, Miguel. (2007). Perceived e-Service Quality (PeSQ) Measurement Validation and Effects on Consumer Satisfaction and Web Site Loyality. Managing Service Quality. Vol.17 Iss:3 pp. 317-340.

Choi, E. J., \& Kim, S. (2013). The Study of the Impact of Perceived Quality and Value of Social Enterprises on Customer Satisfaction and RePurchase Intention, 7(1), 239-252.

Essinger, James \& Wylie, Helen. (2003). Customer Loyality: Devising successful strategies in food and drink. Gramedia.

Harianto, Kevin. (2014). Analisa Service Quality, Food Quality Dan Perceived Value Terhadap Customer Loyalty Konsumen Restaurant Boncafe Manyar Kertoarjo Surabaya Dengan Customer Satisfaction Sebagai Variable Intervening. Jurnal Manajemen Pemasaran.

Harrington, R. J., Ottenbacher, M. C. \& Kendall, K. W. (2011). Fine dining restaurant selection: Direct and moderating effects of customer attributes. Journal of Food Service Business Research, 14(3), 272289.

Hong Qin and Victor R. Prybutok. (2009). Service Quality, Customer Satisfaction, and Behavioral Intentions in Fast Food 
Restaurants. International Journal of Quality and Service Sciences, Vol. 2 No. 2, pp 143-150.

Hong, Briandy. Dan Brahmana, R. K. (2015). Pengaruh Service Quality, Perceived Value, Customer Satisfaction Terhadap Repurchase Intention Pelanggan di Resto Buro Bar Surabaya. Artikel Ilmiah.

Kotler, Philip. (2003). Marketing Management. The Millennium Edition. Prentice-Hall International Inc. New Jersey.

Kotler, Philip. \& Kevin Lane Keller . (2016). Marketing Management. England: Pearson Education Limited .

Krisno dan Samuel. (2013). Pengaruh Persepsi Kualitas Perceived Sacrifie and Perceived Value Terhadap Customer Satisfaction Di Informa Innovative Furnishing Pakuwon. Jurnal Manajemen Petra. Vol 1, h. 1-12.

Kristiana, D. (2013). Pengaruh Kualitas Produk Terhadap Kepuasan Pelanggan Di Rumah Makan "Lesehan 88" Madiun . Jurnal Manajemen Pemasaran , 2.

Lai, T. L. (2004). "Service Quality and Perceived Value's Impact on Satisfaction, Intention and Usage of Short Message Service (SMS)". Informastion System Frontiers, Vol. 6 No. 4, pp. 353-368

Margaretha Fiani S. dan Edwin Japarianto, S.E., M.M. (2012). Analisa Pengaruh Food Quality Dan Brand Image Terhadap Keputusan Pembelian Roti Kecik Toko Roti Ganep's Di Kota Solo. Jurnal Manajemen Pemasaran, Vol. 1, No. 1, 1-6.

Mowen, John C. dan Minor, Michael. (2002). Perilaku Konsumen, Ahli Bahasa: Dwi Kartini Yahya, Erlangga, Jakarta,

Nugroho, A. (2013). Pengaruh Kualitas Lingkungan Fisik, Kualitas Makanan, Kualitas Pelayanan Pada Restaurant Image, Perceived Value, Kepuasan Konsumen, Dan Behavioral Intention . Skripsi.

Norouzi, A., Jafarizadeh, A. A., Karbalaei, M., \& Najafi, Y. (2013). The effective major factors on customer perceived value in service context: The application of ANFIS method, 2(3), 408-416.

Palitali, Alida. (2007). Pengaruh Nilai Pelanggan, Kepuasan Terhadap Loyalitas Nasabah Tabungan Perbankan di Sulawesi Selatan. Jurnal Manajemen dan Kewirausahaan. 9 (1). H. 73-81.

Perwira, Bimo Taufan. (2016). Pengaruh E-Service Quality dan Perceived Value terhadap Kepuasan Pelanggan dan Loyalitas Pelanggan (Survei pada Mahasiswa S1 Universitas Brawijaya yang Melakukan Transaksi Pembelian Online dengan
Mobile Application Tokopedia). Jurnal Administrasi bisnis (JAB).Vol 38 No.2 September 2016.

Prasastono, Ndaru., dan Yulianto, Sri. (2012). Kualitas Produk Dan Kualitas Pelayanan Terhadap Kepuasan Konsumen Kentucky Fried Chicken Semarang Candi. Dinamika Kepariwisataan Vol. XI No. 2.

Purnamawati, D. (2017). Pengaruh Kualitas Produk Dan Harga Terhadap Kepuasan Konsumen Pada Saung Abah Cafe dan Resto Sukabumi. Skripsi.

Soekresno. (2000). Manajemen Food and Beverage Service Hotel. Jakarta: PT Gramedia Pustaka Utama.

Sugiyono. (2014). Statistik Untuk Penelitian. Bandung: Alfabeta.

Sugiyono. (2016). Metode Penelitian Kuantitatif Kualitatif Dan $R \& D$ Cetakan Ke 13. Bandung: Alfabeta.

Sweeney, J. \& Soutar, G. (2003). Are there cognitive dissonance segments?. Australian Journal of Management, 28 (3), 227-249.

Tjiptono, Fandi. (2004). Strategi Pemasaran, Edisi Kedua. Andi. Yogyakarta.

Tjiptono, Fandi. (2006). Pemasaran Jasa. Andi. Yogyakarta.

Z, Yang., and X, Fang. (2004). Online service quality dimensions and their relationships with satisfaction: A content analysis of customer reviews of securities brokerage services, International Journal of Service Industry Management, Vol. 15 No. 3, pp. 302326.

\section{Profil penulis}

1. Clara Candra Komala, Mahasiswa Fakultas Ilmu Administrasi dan Humaniora, Univesitas Muhammadiyah Sukabumi.

Email : claracandra04@gmail.com

2. Nor Norisanti, S. Sos., M. Si, Dosen Fakultas Ilmu Administrasi dan Humaniora, Univesitas Muhammadiyah Sukabumi.

Email : norisanti.ok@gmail.com

3. Asep M. Ramdan, S.E., M.M, Dosen Fakultas Ilmu Administrasi dan Humaniora, Univesitas Muhammadiyah Sukabumi.

Email : amr37ramdan@gmail.com 